Meta

Journal des traducteurs

Translators' Journal

\title{
Strategies for Abating Intercultural Noise in Interpreting
}

\section{Jing Chen}

Volume 52, numéro 3, septembre 2007

URI : https://id.erudit.org/iderudit/016737ar

DOI : https://doi.org/10.7202/016737ar

Aller au sommaire du numéro

\section{Éditeur(s)}

Les Presses de l'Université de Montréal

ISSN

0026-0452 (imprimé)

1492-1421 (numérique)

Découvrir la revue

Citer cet article

Chen, J. (2007). Strategies for Abating Intercultural Noise in Interpreting. Meta, 52(3), 529-541. https://doi.org/10.7202/016737ar

\section{Résumé de l'article}

La nature de l'interprétation et la charge dont elle s'acquitte décident que c'est un acte communicatif interculturel. Il y a deux types de bruit interculturel dérangeant le processus de communication, ceux qui proviennent de l'information envoyée par l'orateur en langage source, et ceux qui viennent du contexte social, culturel et situationnel du processus de communication. Le bruit interculturel empêche le processus d'interprétation et diminue la qualité de l'interprétation. Si la fonction idéale d'un interprète est d'assurer la communication douce entre les parties primaires, alors son rôle est de remédier à n'importe quel bruit interculturel potentiel. Cet article vise alors à formuler les stratégies concrètes d'atténuation de bruit interculturel, y compris des stratégies à long terme, pré-interprétation et pendant l'interprétation.
Ce document est protégé par la loi sur le droit d'auteur. L'utilisation des services d'Érudit (y compris la reproduction) est assujettie à sa politique d'utilisation que vous pouvez consulter en ligne.

https://apropos.erudit.org/fr/usagers/politique-dutilisation/ 


\title{
Strategies for Abating Intercultural Noise in Interpreting
}

\author{
JING CHEN \\ Xiamen University, Xiamen, China \\ jchen_111@yahoo.com.cn
}

\begin{abstract}
RÉSUMÉ
La nature de l'interprétation et la charge dont elle s'acquitte décident que c'est un acte communicatif interculturel. Il y a deux types de bruit interculturel dérangeant le processus de communication, ceux qui proviennent de l'information envoyée par l'orateur en langage source, et ceux qui viennent du contexte social, culturel et situationnel du processus de communication. Le bruit interculturel empêche le processus d'interprétation et diminue la qualité de l'interprétation. Si la fonction idéale d'un interprète est d'assurer la communication douce entre les parties primaires, alors son rôle est de remédier à n'importe quel bruit interculturel potentiel. Cet article vise alors à formuler les stratégies concrètes d'atténuation de bruit interculturel, y compris des stratégies à long terme, préinterprétation et pendant l'interprétation.
\end{abstract}

\begin{abstract}
The nature of interpreting and the task it fulfills decide that it is an intercultural communicative act. There are two types of intercultural noise disturbing the communication process, that originating from the information sent by the source-language speaker, and that coming from the social, cultural and situational context of the communication process. Intercultural noise impedes the interpreting process and debases the quality of interpreting. If the ideal function of an interpreter is to ensure smooth communication between the primary parties, then his role is to remedy any potential intercultural noise in the channel. This paper then aims to formulate concrete intercultural noise-reducing strategies, which include long-term strategies, pre-interpreting strategies and duringinterpreting strategies.
\end{abstract}

\section{MOTS-CLÉS/KEYWORDS}

communication process, intercultural noise, interpreting process, quality of interpreting

\section{Interpreting as an Intercultural Communicative Act}

Interpreting is a form of mediating across boundaries of languages and cultures. Interpreters are expected to have sufficient linguistic knowledge in order to translate correctly. But the barriers to communication are more than linguistic ones, because the two speakers not only speak different languages but have different cultural backgrounds. Interpreters must bridge the cultural and conceptual gaps as well as the linguistic gaps between the two speakers.

The interpreter's task is to help the parties communicate. To this end, the interpreter is required to decode the source linguistic signal in order to understand the meaning of the message that is being sent, and then has to re-code that information into the target language rather than merely rearrange the structure of observable linguistic units or adjust the linguistic coding. What is involved is a complex, multi- 
layered, dynamic process through which meaning is exchanged. In interpreting, as Per Linell (1999) mentions, linguistic practices are not independent of the speaker's and listener's perspectives, particularly their cultural frames. Interpreting is "an act of communication which attempts to relay, across cultural and linguistic boundaries, another act of communication." (Hatim and Mason 1997: 1)

When setting up an approach to defining interpreting as an intercultural communicative act, we should first of all grasp the concept of culture in translation. According to Snell-Hornby (1995), culture consists of the organization of things, people, behavior or emotions which one needs to know and master in order to conform to what is expected from one's social roles. There are three important points pertaining to the definition: 'firstly, the concept of culture as a totality of knowledge, proficiency and perception; secondly, its immediate connection with behavior and events, and thirdly, its dependence on expectations and norms, whether those of social behavior or those accepted in language usage'(Snell-Hornby 1995:40). This concept of culture is fundamental in the approach to translation, and specifically here to interpreting.

\section{Intercultural noise in interpreting}

The co-presence of two or more different cultural systems in interpreter-mediated communication is considered to give rise to divergence between the receiver's textual and linguistic expectations on the one hand and the way the sender actually presents his message on the other. The intercultural factors are thus viewed as a source of potential noise.

The concept of noise is borrowed from the theory developed by the mathematicians represented by Claude E. Shannon and Norbert Weaver (1949), referring to anything added to the signal that is not intended by the information source. Shannon clearly designed his theory as a mathematical model that does not take into account human emotions and experiences and semantic meaning. Like noise defined in the mathematical theory of communication, intercultural noise in interpreting is also spurious information, which is not intended by the information source, and which increases uncertainty. But it is related to the portion of cultural or situational information, in patterns of language and thought and in forms of activity and behavior, which creates barriers to the flow of effective communication of interpreting.

Given the nature of the communication process of interpreting, it is believed that there are two types of intercultural noise disturbing the communication process of interpreting (see Figure 1). The first type of noise originates from the information sent by the source-language speaker, which takes the form of verbal and non-verbal signals. It results from any failure to notice and process the cultural factors contained in the source language, source paralanguage and source kinesics. 
FIGURE 1

Communication Process of Interpreting Disturbed by Intercultural Noise

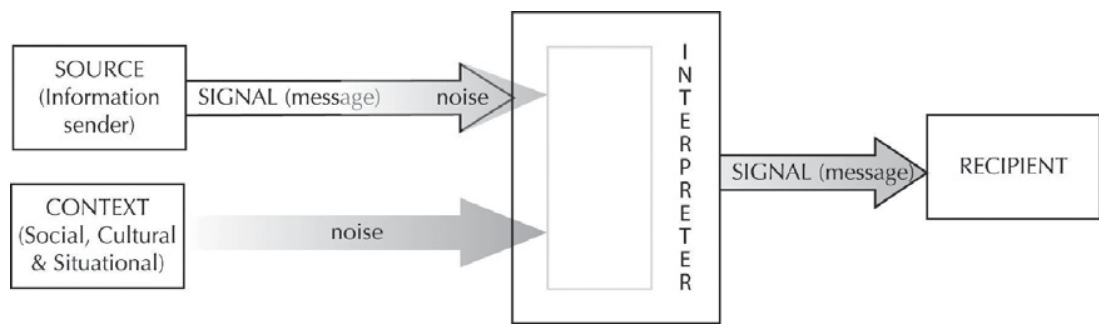

For example, a Chinese points his index finger at someone, and shouts, “你是不 是想砸了我的饭碗?” (ni shi bu shi xiang za le wo de fan wan?) [literally: Do you mean to smash my rice bowl?] To interpret this utterance, the interpreter should observe the intercultural noise in three aspects.

Body language: pointing one's index finger at someone is regarded as impolite or even a threat in Chinese culture.

Intonation: rising tone in this case shows the speaker's anger.

Language: “砸饭碗” (za fan wan) [literally: smash one's rice bowl] here connotes "making someone lose his job or money-making opportunity."

The second type of noise in the model comes from the social, cultural and situational context of the communication process. The current research, based on Scollon's (1995: 22) seven components for a grammar of context, specifies the context of interpreter-mediated communication as scene, key, participants and message form.

Scene involves the setting, topic, genre, and purpose of the communication to be interpreted. Key is a term borrowed from music to refer to the tone or the mood of a communication. Examples of the keys in a communication situation involving interpreters include being serious, casual, solemn and entertaining. Participants in an interpreter-mediated communication refer to the two primary parties: the source information sender and the receiver of the target text. Three aspects of participants need to be taken into consideration in reading the contextual grammar of speech situations: who they are, what roles they take and the sheer number of participants. Message form is the effective medium used for communication. In interpretermediated communication, the media can be either simply acoustic or acoustic and visual.

When an interpreting process gets started, the two types of noise discussed above reach the interpreter. If he fails to identify the noise and take measures to treat it, the noise will be then carried over in the second information flow initiated by the interpreter and the whole communication will be disturbed.

In Warren Weaver's (1966:16) opinion, if noise is introduced, the received message contains certain distortions, errors, extraneous material, which would certainly lead to increased uncertainty. This uncertainty that arises because of the influence of noise affects the interpreter-mediated communication at three levels: technical, semantic and influential.

The technical problems involve the accuracy of transference of information from sender to receiver (Weaver 1966: 15). If the technical level of the interpreter-mediated 
communication is polluted by intercultural noise, it is because the cultural factors in the received message have basically been neglected by the interpreter.

To look at an example, take "Israel is a Teflon country." Teflon is originally a Dupont trademark of a non-stick plastic coating. It connotes "the ability to escape criticism” in this context, and can be put into “以色列是个免遭批评的国家, 就像 拥有一层特氟龙保护膜一样. (yi se lie shi ge mian zao pi ping de guo jia, jiu xiang yong you yi ceng te fu long bao hu mo yi yang.) [literally: Israel is able to escape criticism, just like being coated with Teflon.] A word-for-word Chinese interpretation like '以色列是个特氟龙国家' (yi se lie shi ge te fu long guo jia) [literally: Israel is a Teflon country.] does not carry with it the cultural connotation, and is incomprehensible, and the communication can be said to be affected by intercultural noise at technical level.

Semantic problems arise from the interpretation of meaning by the receiver, as compared with the intended meaning of the sender (Weaver 1966: 15). In the context of interpreter-mediated communication, if the semantic level is affected by intercultural noise, the intended meaning of the sender is usually misinterpreted or distorted.

An English university professor is commenting on the solemnity of the teaching profession, 'Being a teacher is being present at the creation, when the clay beings begin to breathe', meaning in Chinese “老师是创造的见证人, 目睹生命呼吸成长” (lao shi shi chuang zao de jian zheng ren, mu du sheng ming hu xi cheng zhang). If it is put into Chinese by the interpreter as “自盘古开天地以来, 老师便是创造的见证人' $z i$ pan gu kai tian di yi lai, lao shi bian shi chuang zao de jian zheng ren) [literally: Since the start of history, a teacher is being present at the creation.], the culture-loaded part of 'the clay beings begin to breathe' is misunderstood and misinterpreted due to the interpreter's ignorance of the Christian culture, a communication barrier created by the intercultural noise at the semantic level.

Problems of influence occur when the meaning conveyed to the receiver does not lead to the desired conduct on his part. "It may seem at first glance undesirably narrow to imply that the purpose of all communication is to influence the conduct of the receiver. But with any reasonably broad definition of conduct, it is clear that communication either affects conduct or is without any discernible and provable effect at all.” (Weaver 1966: 15) When the influential level of the interpreter-mediated communication is disturbed by intercultural noise, communication failure or breakdown occurs. For instance, the speaker's invitation fails to be extended to the target receiver, or the receiver does not get the message because it is beyond his understanding.

Strategies for abating the noise

Intercultural noise impedes the interpreting process and debases the quality of interpreting. If the ideal function of an interpreter is to ensure smooth communication between the primary parties, then his role is to remedy any potential intercultural noise in the channel by adjusting the culturally determined peculiarities of the source text to the culturally determined expectations of the receiver. This paper attempts to formulate concrete strategies as to how to reduce intercultural noise, which are analyzed into long-term strategies, pre-interpreting strategies and during-interpreting strategies. 


\section{Long-term strategies}

Long-term strategies are employed to enhance interpreters' intercultural awareness, which promotes open-mindedness beyond one's own cultural border, contributing to a better understanding between people and of the text and context, thus avoiding interpreting in which target texts are divested of their very otherness. To cultivate intercultural awareness should be a long-term task for trainee interpreters and an important part of any interpreter training programs. This is not a focus of this research.

But what's worth emphasizing is that the interpreter's bicultural competence cannot merely consist of a competence in the cultures he works with but must also comprise a competence between them. In the current study, the interpreter's intercultural awareness refers to the capacity for noticing, for understanding, and for offsetting the intercultural noise in interpreting process.

\section{Pre-interpreting strategies}

Pre-interpreting strategies involve textual preparatory work for interpreting. We assume that text analysis be part of interpreter's competence and a crucial procedure in interpreting. It aims to arouse the interpreter's awareness of the textual environment in their efforts to offset the intercultural noise.

The interpreting-oriented text analysis involves the analysis of the source text and that of the interpreting skopos.

The communicative function of the source text is represented by the extratextual and intratextual factors of the communicative situation in which the source text fulfills its function. Extratextual factors are analysed by enquiring about the sender of the text, the sender's intention, the recipient the text is directed at, the medium the text is communicated by, the place and time of text production and text reception and the motive of the communication.

Intratextual factors are analyzed by enquiring about the subject matter the text deals with, the information or content presented in the text; the construction of the text, the non-linguistic elements accompanying the text and the lexical characteristics and syntactic structures found in the text.

In specifying the interpreting skopos, i.e. the intended function of the target text, the interpreter has to look into two aspects before any interpreting task: the interpreting instruction and the listener's expectation.

The interpreting instruction can be obtained by asking the following set of WHquestions with respect to the target text, based on the so-called New Rhetoric formula (Nord 1991: 36).

Who is to transmit

to whom

what for

by which medium

where

when

why

a text

with what function? 


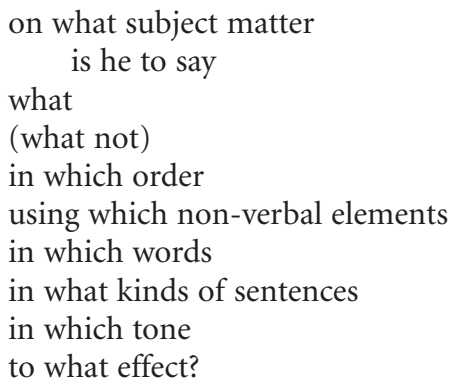

The target listener's expectation is another issue of concern for the interpreter in formalizing the interpreting skopos. Interpreting is not a process of transcoding languages, but an act of communication, which is embedded in a given situation, and conditioned by the sociocultural background. Interpreting is aimed at a receiver much more than the interpreter himself, a rater, or a corrector of the product. After the interpreter receives a verbal signal from the sender which consists of informational content and its package (the words and linguistic structures of the speech, the voice and delivery and non-verbal signal), he should interpret in a way that enables the target text to function in the situation in which it is used and with the people who want to use it and in the way they want it to function.

For instance, typical openings of Chinese speeches are usually characterized as emotional and full of flowery words. Literal translation of every word cannot always help guarantee the best possible quality of interpretation under the circumstances.

仲春四月, 繁花似锦, 芙蓉园内, 春光明媚。我系全体师生怀着喜悦的心情迎来 了八十周年系庆。(zhong chun si yue, fan hua si jin, fu rong yuan nei, chun guang ming mei. Wo xi quan ti shi sheng huai zhe xi yue de xin qing ying lai le ba shi zhou nian xi qing.) [literally: In the spring of April, flowers are blooming and the campus of Furong boasts a sunlit and enchanting scene of spring. With delight, all the faculty and students are welcoming the 80th anniversary of the department.]

Another tendency is that Chinese speakers purposely degrade themselves in the speech as a token of modesty and humbleness, which are regarded as virtues in the Chinese culture. For example,

由于本人学识浅薄, 加之准备不充分, 所讲之处肯定多有疏漏和不妥, 请大家包 涵。(you yu ben ren xue shi qian bo, jia zhi zhun bei bu chong fen, suo jiang zhi chu ken ding duo you shu lou he bu tuo, qing da jia bao han.) [literally: I would expect for your tolerance to the oversight and error in my speech due to my insufficient preparation and limited knowledge.]

It is clear to all that linguistic fidelity in this context may cause misunderstanding and some distortions of meaning. The verbosity and the use of flowery expressions characteristic of Chinese speeches may not only sound superficial and insincere to the receiver from a different culture, but also fail to convey the speaker's intention, thus constituting barriers to communication. Here, the interpreter has to make an intelligent sacrifice of those parts he thinks can be omitted at least cost to his audience's understanding. For the first examples, "happiness in the beautiful season" is the core sense, while the second extends the speaker's appreciation of the listener's attendance. By conveying these messages, the interpreter will have achieved maximum 
economy of expression and fulfilled the communication function while respecting the sense of the original.

\section{During-interpreting strategies}

Source text analysis aims to control compatibility of the target skopos with the given source text and then to find out which elements in the source text can be preserved and which have to be adapted so as to comply with the interpretation skopos. This section discusses how source information disturbed by intercultural noise is transferred into communicative target language. Depending on the result of the pre-interpreting text analysis, different forms of interpreting strategies can be adopted on a scale extending from extreme fidelity at one end to extreme liberty at the other, or, from full preservation at one end to full adaptation at the other.

\section{Preservation}

The strategy of preservation is adopted when the interpreter is able to keep as much as he can of the original references without defeating the communicative intentions. In this case, the exotic character is believed by the interpreter to be widely acceptable to the target receiver.

Preservation can take the form of transliteration and literal translation. “太极” (tai ji) rendered into “tai chi," “旗袍” (qi pao) into “chi-pao" “gene” into “基因”( $j i$ yin) and “coca cola” into “可口可乐”(ke kou ke le) are examples of transliteration. Literal translation is adopted when the interpreter makes use of the linguistic transparency of the culture-loaded items and translates them into the target language. The target version can still be recognized as belonging to the cultural system of the source text but is well accessible to the target listeners, such as "hold out the olive branch" interpreted into “伸出橄榄枝”(sheng chu gan lan zhi), “crocodile tears” into “鲻鱼眼 泪” (e yu yan lei) and “纸老虎”(zhi lao hu) into “paper tiger.”

\section{Adaptation}

In most cases, a multitude of adaptation tactics on all levels, phonology, lexicon, syntax and discourse, should be employed to deal with the information carrying with it intercultural noise. Generally speaking, adaptations must be warranted when close, formal interpreting results in miscommunications. The following remarks are made by the president of Tsinghua University.

一流大学, 首先是教学、科研水平达到世界一流, 但能否想象, 到2011年我校两 万多名师生员工还用筷子敲着饭碗, 拿着饭票, 排着长队买饭呢? 当然是不行 的。这就给我们提出了一个问题: 清华大学要建成世界一流大学, 我们后勤怎么 办? 我们饮食中心怎么办? (yi liu da xue, shou xian shi jiaoxue, key an shui ping da dao shi jie yi liu, dan neng fou xiang xiang, dao 2011 nian wo xiao liang wan duo ming shi sheng yuan gong hai yong kuai zi qiao zhe fan wan, na zhe fan piao, pai zhe chang dui mai fan ne? dang ran shi bu xing de. Zhe jiu gei wo men ti chu le yi ge wen ti: qing hua da xue yao jian cheng shi jie yi liu da xue, wo men hou qin zen me ban? Wo men ying shi zhong xin zen me ban?) [literally: A world class university should live up its academic level to the world standards. But can we imagine in the year 2011, about 20,000 staff 
and students still beat their rice bowls with chopsticks, hold meal tickets and line up in long queues for meals in canteens. Of course this is not acceptable. This poses a question to us: if Tsinghua is turned into a world class university, what our ancillary service should do, and how our catering centers should do?]

The passage is interpreted into:

If Tsinghua is turned into a world first-class university, not only should its academic level live up to the world standards, but also its catering services. You cannot imagine about 20,000 staff and students still lining up impatiently in long queues for meals in canteens by the year 2011, our centennial. I don't think it's acceptable. Therefore, the issue of how to improve our ancillary services and catering centre should be put on the top of the agenda.

The English version above has been adapted in the following aspects: firstly, the thesis and the conclusion are clearly stated at the very beginning and end of the text, which is in keeping with the thought patterns and expectations of the target listeners. Secondly, “用筷子敲着饭碗, 拿着饭票, 排着长队” (yong kuai zi qiao zhe fan wan, na zhe fan piao, pai zhe chang dui) was interpreted into "lining up impatiently in the long queue," because a word for word interpretation of the first two phrases, which bear Chinese flavor does not really carry the implication of "impatience." Thirdly, “我 们后勤怎么办? 我们饮食中心怎么办? ”(wo men hou qin zen me ban? Wo men yin shi zhong xin zen me ban?) was transferred into "how to improve our ancillary service and catering centers" instead of "what our ancillary service and catering centers should do," as better representation of the pragmatic meaning of the source text. Fourthly, “当然是不行的” (dang ran shi bu xing de) was interpreted into “I don't think that is acceptable" instead of "of course that is not acceptable," because the latter sounds unpleasant to the target listener. Finally, "our centennial" was added to explain "the year 2011," as background information to the target listener.

What is discussed in the following are some of the most commonly-used coping tactics. The list is by no means exhaustive, but takes into accounts features of interpreting acts, thus serving as good illustration of how communication disturbed by intercultural noise can be remedied and how communicative intentions can be accomplished in interpreting.

\section{Explaining or paraphrasing}

The tactic of explaining can be used when the cultural references have no direct equivalents in the target language, or when the interpreter feels the explanation facilitates the recipient's comprehension.

Here is an example. An English professor of linguistics is talking about the English language to a group of Chinese university students.

Let's face it - English is a crazy language. There is no egg in eggplant nor ham in hamburger; neither apple nor pine in pineapple. English muffins weren't invented in England nor French fries in France. Sweetmeats are candies while sweetbreads, which aren't sweet, are meat.

Obviously, literal equivalents in Chinese cannot convey the intended message to the listeners. The interpreter should explain to their listeners differences between the 
literal meaning of each component of the words and the lexical meaning. The translation can go like this:

我们必须面对这样一个事实, 英语是一种说不清道不明的语言。茄子里既没 egg（蛋）也没plant（植物），却被称作eggplant（蛋植物）；汉堡里不含 ham (火腿)，却被称做hamburger (火腿堡) ; 菠萝里既没苹果apple, 更没松 树pine, 却是pineapple (松树苹果)。英式松饼 (英语是English muffins) 可不是 在英国发明的; 油炸土豆条英语是French fries，意即法式油炸土豆条，但这东西 决不是法国人发明的; sweetmeat不是甜肉, 而是一种糖果; sweetbread不是甜面 包, 却是一种肉类。

(wo men bi xu mian dui zhe yang yi ge shi shi, ying yu shi yi zhong shuo bu qing dao bu ming de yu yan. Qie zi li ji mei dan, ye mei zhi wu, que bei cheng zuo dan zhi wu; han bao li bu han huo tui, que bei cheng zuo huo tui bao; bo luo li ji mei pin guo, gen mei song shu, que shi song shu ping buo. Ying shi song bin ke bu shi ying guo fa ming de; you zha tu dou tiao yi ji fa shi you zha tu dou tiao, dan zhe dong xi jue bu shi fa guo ren fa ming de; sweetmeat bu shi tian rou, er shi yi zhong tang guo; sweetbread bu shi tian mian bao, que shi yi zhong rou lei.)

\section{Domestication}

Domestication is the representation of source culture-loaded references by target culture expressions. It is the result of a comparison of the way in which the original receivers understand and appreciate the text and the way in which receivers of the interpreted text understand and appreciate the interpreted text. In the following examples, the cultural content in the source text is all adapted in the target versions in order to be accessible to the target listeners: "give him an inch, and he will take a mile" is interpreted into得寸进尺(de cun jin chi) [literally: give him a Cun, and he will take a Chi], “(make) bricks without straw” into 无米之炊 (wu mi zhi chui) [literally: cooking without rice], “己所不欲, 勿施与人” ( $j i$ suo bu yu, wu shi yu ren) [literally: if you don't want to do it yourself, don't expect others to do it] into "do unto others as you would have them do unto yourself," “攀龙附凤”(pan long fu feng) [literally: climb up to a dragon and hold a phoenix] into "ride on somebody's coat tails."

\section{Restructuring}

Textual differences between the source text and the target text may warrant the use of restructuring.

The following two passages illustrate how Chinese and English differ in maintaining discourse coherence.

在我国的福建省, 有一美妙去处。它碧海环抱, 山峦叠翠, 花香袭人, 鸟声婉 转。它就是厦门的鼓浪屿。(zai wo guo dong nan yan hai de fu jian sheng, you yi mei miao qu chu. Ta bi hai huan bao, shan luan die cui, hua xiang xi ren, niao sheng wan zhuan. Ta jiu shi xia men de gu lang yu.) [literally: In Fujian Province of China, there is a beautiful scenic spot. It is surrounded by the sea and enjoys lush green forests, fragrant flowers and songbirds. It is Gulangyu Islet in Xiamen.] 
The target version is restructured as:

One of Fujian's finest spots is Gulangyu Islet in Xiamen. It is surrounded by the sea and enjoys lush green forests, fragrant flowers and songbirds.

Note that the topic in this text, Gulangyu Islet, appears at the end of the Chinese text, but the beginning of the English version. This is a reflection of the different information structures and thought processes of English and Chinese. English utterances tend to flow from thematic information to supporting, explanatory or supplementary information in an analytic and linear manner, while Chinese utterances usually follow the opposite direction.

In stark contrast to logical thinking and rational cognition in English rhetoric, Chinese is characterized by spirally-developed exposition, implicit thesis and lack of topic sentences. In this context, interpreters are expected to clarify the thesis in Chinese and express it more directly in the English target text.

For example, Long Yongtu, the China's chief WTO negotiator was once asked by a foreign correspondent whether he ever felt frustrated during the negotiations. His reply was as follows:

我觉得这场谈判全国都在关注。有时候谈判为了一些大的战略上的利益需要做出 一些小的政策上的让步。这时候作为谈判代表来讲, 心里是很不舒服的。但是有 时候觉得从大局来讲, 是要这样的。这时候你就想开了。(wo jue de zhe chang tan pan quan guo dou zai guan zhu. You shi hou tan pan wei le yi xie de zhan lue shang de xu yao zuo chu yi xie xiao de zheng ce shang de rang bu. Zhe shi hou zuo wei tan pan dai biao lai jiang, xin li shi hen bu shu fu de. Dan shi you shi hou jue de cong da ju lai jiang, shi yao zhe yang de.zhe shi hou ni jiu xiang kai le.) [literally: I knew the whole nation was watching us. There were times when we had to make some minor policy-related concessions for strategic reasons. As a negotiator, I did not feel good about that, but I realized that we had no choice and it was the best we could do. That made me feel better.]

Though no direct answer was given to the question of whether he felt frustrated, no Chinese would fail to work out the implication: yes, I did feel frustrated now and then. But when interpreted into English, the utterance should be either started or ended with a direct answer as "Yes, I certainly did sometimes," in order to facilitate the target listener's comprehension.

\section{Generalization}

When interpreters are incapable of finding linguistic equivalents for the cultural references in the source language or when literal translation leads to communication failures, one possible solution is to reformulate the message in a less accurate manner by using a superordinate in the case of a single word, or by constructing a more general segment in the case of a whole clause. The following Chinese text is part of a flowery speech depicting various osmanthus trees in Guilin Park:

一进入桂林公园, 阵阵桂香就扑鼻而来。芳香四溢、挂满金花的金桂; 香气浓 郁、花色如雪的银桂; 红黄交融、花多味浓的紫砂桂; 花色如银、季季开花的四 季桂。各色桂花竞相开放, 争妍謧美。(yi jin ru gui lin gong yuan, zhen zhen gui xiang jiu pu bi er lai. Fang xiang si y,i gua man jin hua de jin gui; xiang qi nong yu, hua se ru xue de yin gui; hong huang jiao rong, hua duo wei nong de zi sha guil; hua se ru xue, ji ji kai hua de si ji gui. Ge se gui hua jing xiang kai fang, zheng yan pi mei.) [literally: 
Entering Guilin Park, we are greeted by sweet smell. The Jin osmanthus trees are full of fragrant golden flowers. Flowers in the Yin osmanthus trees are fragrant and as white as snow. The flowery Zisha osmanthus trees, red and yellow, send forth strong fragrance. Silver flowers are in blossom in the Siji osmanthus trees all around the season. The flowers vie each other for glamour.]

It can be generalized into:

Entering Guilin Park, we are greeted by sweet smell. Flowers from various types of osmanthus trees in different colors are in full bloom, which pervade the whole garden with the fragrance of their blossoms.

\section{Simplification}

Deliberate simplification on the part of the interpreter is a technique to be used sparingly and carefully. But it has been argued that an interpreter's first duty is not so much to be faithful to the speaker's words as to maximize communication. Simplification can bridge communication gaps. For instance, simplification can apply to any case of a speaker talking over the heads of the target listener. The interpreter may very well be able to cope with the speech, but a faithful rendering would leave the audience confused. If, for example, a group of teenagers is being provided information on the Agricultural Policy of the European Union, they need to understand the explanations they receive. 'If the CIF price of produce at the border is below the guideline price as determined under the Common Market Organization, then a levy, which is not a tariff duty, is imposed', is the kind of information young laymen will most probably find impenetrable, unless most of the terms are explained by the speaker. The interpreter may find it better to interpret in this way, “如果农产品进入 欧盟的价格低于官方市场价, 那么就要对其征收农业税。'(ru guo nong chan pin jin ru ou meng de jia ge di yu guan fang shi chang jia, na me jiu yao dui qi zheng shou nong ye shui.) [literally: If farm produce comes into the European Union at a price below the official EU market price, a special agricultural levy is imposed.]

In the following example, Lao Zhang meets his American friend Bob who doesn't look well, and says:

“哎呀, 你脸色看上去有点苍白呀, 哪儿不舒服? 要多喝点水。天气凉, 要多穿 点。最好去看看医生。我觉得中医比较管用, 你想不想去试试? ”( a i ya, ni lian se kan shang qu you dian cang bai, na er bu shu fu? Yao duo he dian shui. Tian qi liang, yao duo chuan dian. Zui hao qu kan kan yi sheng. Wo jue de zhong yi bi jiao guan yong, ni xiang bu xiang qu shi shi?) [literally: Ah, you look so pale. What's wrong with you? You have to drink more water. It's getting cool. You need to put on more clothes. You'd better go to see the doctor. Traditional Chinese medicine will help. Do you want to try it?]

In saying this, he is extending to his friend typical Chinese greetings appropriate to this context. If what he says is interpreted into English literally, Bob will feel his privacy being invaded. What needs to be interpreted is the intended message "Are you OK? You don't look well. Are you taking anything for it?", in other words, the pragmatic content of the speech. 


\section{Omission}

Omission is implemented when the interpreter considers the information carrying intercultural noise unacceptable on ideological or stylistic grounds, or they think that it is not relevant enough for the effort of comprehension required of their listeners, or that it is too obscure and it is inappropriate to use procedures such as explanation, simplification. It refers to the case where an interpreter believes that interpretation would be worse than non-interpretation.

Take Chinese introductory remarks as an example. China has long operated a system of so-called status identity which defines the specific status for each member in the society. This can partly explain why the following is a typical Chinese way of introducing distinguished guests.

下面我们热烈欢迎下一位演讲者。他就是 $x x$ 大学物理研究所所长兼美国 $x x$ 大学客 座教授、中国 $x x$ 学会理事、 $x x$ 省 $x x$ 学会会长、博士生导师, 著名的德高望重的物 理学家xxx教授。(xia mian wo men re lie huan ying xia yi wei yan jiang zhe. Ta jiu shi $X X$ da xue wu li yan jiu suo suo zhang jian mei guo XX da xue ke zuo jiao shou, zhong guo $x x x u e$ hui li shi, $x x$ sheng $x x x u e$ hui hui zhang, bo shi sheng dao shi, zhu ming de de gao wang zhong de wu li xue jia $x x x$ jiao shou.) [literally: Now let's welcome the next speaker. $\mathrm{He}$ is the director of the Physics Institute of $\mathrm{xx}$ University, visiting scholar of $\mathrm{xx}$ University in the United States, Member of the council of the China xx Society, Director of $\mathrm{xx}$ Society of $\mathrm{xx}$ Province, $\mathrm{PhD}$ supervisor, a famous and honorable physicist and professor.]

In contrast to the status identity system in Chinese society, equality and freedom have long taken its place in the West. Wherever appropriate, part of the source language information should be omitted to adapt to the Western way of introducing people:

Now, it is my great honour to invite our next speaker, Prof xxx, a famous physicist from $\mathrm{xxx}$ University to take the floor.

\section{Conclusion}

It is important to establish that communication involving an interpreter is always an instance of intercultural communication. Interpreting is a process of conveying messages across linguistic and cultural boundaries, within which intercultural noise constitutes a communication barrier. The two types of noise, one originating from the information in the form of verbal and non-verbal signals sent by the sourcelanguage speaker, the other from the context of the communication process, disturb the communication at technical, semantic and influential level. To facilitate communication and understanding between a speaker and a listener who differ with respect to both language and culture, the interpreter is required to function as a cultural mediator, identifying and subtracting the disruptive information from the received message by means of long-term strategies, pre-interpreting strategies and duringinterpreting strategies.

\section{REFERENCES}

Hatim, B. and I. Mason (1997): The Translator as Communicator, London, Routledge.

Lineld, P. (1999): “Interpreting as Communication," in Gambier, Y. et al. (eds.), Conference Interpreting: Current Trends in Research, John Benjamins. 
Nord, C. (1991): Text Analysis in Translation, Amsterdam, Rodopi.

Scollon, R. and W. Scollon (1995): Intercultural Communication: A Discourse Approach, Oxford, Blackwell.

Shannon, C. and W. Weaver (1949): The Mathematical Theory of Communication, Urbana, University of Illinois Press.

Snell-Hornby, M. (1995): Translation Studies: An Integrated Approach, John Benjamins.

Weaver, W. (1966): “The Mathematical Theory," in Sмith, A. (ed.), Communication and Culture, Holt, Rinehart and Winston. 